\title{
Implementasi Smart Learning dan Penguatan Kompetensi Guru Milenial Era Disrupsi di Kanagarian Lubuk Batingkok Kelurahan Tigo Balai Kecamatan Harau Kabupaten 50 Kota Provinsi Sumatera Barat
}

\author{
Resmi Darni ${ }^{1}$, Lativa Mursyida ${ }^{2}$ \\ Universitas Negeri Padang, \\ Jl. Prof. Dr. Hamka, Air Tawar Barat, Sumatera Barat ${ }^{1,2}$ \\ Email: resmidarni@ft.unp.ac.id ${ }^{1}$
}

\begin{abstract}
ABSTRAK
Artikel ini membahas tentang permasalahan yang terjadi dalam pembelajaran tahfidz di TAUD AlFatihah dimana metode tabarak yang sebelumnya di gunakan dalam pembelajaran tahfidz bagai anak usia dini di TAUD Al- Fatihah belum mampu untuk menyelesaikan permasalahan pembelajaran dimasa pandemi COVID-19. Sulitnya proses belajar selama pandemi COVID-19 ini membuat TAUD ALFatihah perlu mencari metode dan media belajar yang baru. Oleh sesbab itu untuk mempermudah pembelajaran tahfidz di masa pandemi ini diperlukan metode pembelajaran berbasis smart learning. Tujuan dari kegiatan pengabdian ini adalah untuk membantu TAUD Al-Fatihah dalam menyediakan media pembelajaran yang dinamis dan mempermudah para peserta didik dalam menghafal Al-Qur'an tanpa terganggu oleh kondisi pandemi COVID-19, disamping itu kegiatan ini juga membatu para guru dalam meningkatkan kompetensi IT yang dapat mendukung kegiatan pembelajaran daring selama pandemi COVID-19. Metode yang digunakan dalam kegiatan ini adalah metode pelatihan dan pendampingan dalam pembuatan media pembelajaran tahsin dan tahfidz bagi para peserta didik selama kegiatan off-class. Media pembelajran yang dirancang ini dibuat dalam bentuk modul pintar berbasis multimedia serta video pembelajaran dan evaluasi yang dapat di akses secara offline sehingga tidak membebankan orang tua murid dalam kegiatan pembelajaran anak. Hasil akhir dari kegiatan pengabdian ini adalah sebuah media pembelajaran berbentuk modul elektronik serta terdapat peningkatan hasil pelatihan sebesar $21 \%$ nilai rata-rata pre test 57,78 dan Post test 88,52.
\end{abstract}

Kata kunci: TAUD Al- Fatihah, Tahfidz, Smart Learning, Elektronik Modul, Kompetensi

\begin{abstract}
This article discusses the problems that occur in learning tahfidz at TAUD Al-Fatihah where the tabarak method previously used in learning tahfidz like early childhood at TAUD Al-Fatihah has not been able to solve learning problems during the COVID-19 pandemic. The difficulty of the learning process during the COVID-19 pandemic has made TAUD AL-Fatihah need to find new learning methods and media. Therefore, to facilitate the learning of tahfidz in this pandemic, a smart learning-based learning method is needed. The purpose of this service activity is to help TAUD Al-Fatihah in providing dynamic learning media and making it easier for students to memorize the Al-Qur'an without being disturbed by the conditions of the COVID-19 pandemic, besides that this activity also helps teachers improve competence IT that can support online learning activities during the COVID-19 pandemic. The method used in this activity is the method of training and mentoring in making tahsin and tahfidz learning media for students during off-class activities. This learning media designed is made in the form of multimedia-based smart modules as well as learning and evaluation videos that can be accessed off line so that it does not burden the parents of students in children's learning activities. The final result of this service activity is a learning media in the form of an electronic module and there is an increase in training results by $21 \%$, the average value of pre-test is 57.78 and Posttest is 88.52 .
\end{abstract}

Keywords: TAUD Al-Fatihah, Tahfidz, Smart Learning, Electronic Module, Competence 


\section{PENDAHULUAN}

Kabupaten Lima Puluh Kota adalah sebuah kabupaten di Provinsi Sumatra Barat, Indonesia. Ibu kota kabupaten ini terletak di Sarilamak. Kabupaten ini memiliki luas wilayah 3.354,30 $\mathrm{km}^{2}$ dan berpenduduk sebanyak 348.555 jiwa. Seiring dengan tingginya tingkat pertumbuhan penduduk di kabupaten ini, maka banyak sekolah-sekolah yang dibuka baik itu swasta maupun negeri, salah satunya adalah Tahfidz Anak Usia Dini (TAUD) Al-Fatihah yang menjadi sekolah mitra pada Program Kemitraan Masyarakat (PKM) ini. Tahfidz Anak Usia Dini (TAUD) Al-Fatihah beralamat di Tigo Balai kanagarian Lubuk Batingkok kecamatan Harau, kabupaten 50 Kota. Sekolah ini berdiri pada akhir tahun 2019, di atas tanah seluas $1500 \mathrm{M}^{2}$ dengan status milik sendiri. Sekolah ini dipimpin oleh Ustadzah Rahmawati dengan jumlah tenaga pengajar sebanyak 5 orang, jumlah siswa tahun ajaran 2019-2020 sebanyak 42 orang.

Peningkatan kecerdasan pada Anak Usia Dini adalah salah satu hal yang sangat penting dilakukan, hal ini bertujuan untuk membantu pertumbuhan, perkembangan jasmani dan rohani agar anak memiliki kesiapan untuk memasuki ke tingkat sekolah yang lebih lanjut. Rentang umur Anak Usia Dini yaitu 0-6 tahun, usia ini disebut juga dengan usia emas (Golden Age) (Sugeng et al., 2019), karena pada masa tersebut anak akan mengalami perkembangan yang begitu signifikan, baik itu dari segi fisik, intelektual, sosial emosional, maupun bahasa. Pada usia ini anak mulai mengenal sekolah, mulai berkelompok, masa menjelajah, meniru, aktif, kreatif dan senang bermain.

Pemahaman tentang pentingnya masa usia dini, berdampak pada kebijakan pemerintah saat ini. Salah satu kebijakan tersebut tertuang dalam UU RI No 20 Tahun 2003 tentang Sistem Pendidikan Nasional yang mewujudkan suasana belajar dan proses pembelajaran agar peserta didik secara aktif mengembangkan potensi dirinya untuk memiliki kekuatan spritiual keagamaan, pengendalian diri, kepribadian, kecerdasan, akhlak mulia serta ketrampilan yang diperlukan dirinya, masyarakat, bangsa dan negara (Ridho et al., 2015; Nugraha et al., 2015).

Salah satu kebiasaan pada anak usia dini adalah suka meniru dan mengulang-ulang perkataan, oleh sebab itu pada masa ini sangat baik sekali untuk menirukan dan mengulang-ulang hal yang bersifat positif, salah satunya adalah dengan menghafal AlQur'an. Banyak metode yang digunakan agar anak mudah dalam menghafal Al-Qur'an, namun perlu diperhatikan bahwa tidak semua metode tersebut dapat dengan mudah diterapkan pada Anak Usia Dini. Metode penghafalan Al-Qur'an yang diterapkan di 
TAUD Al-Fatihah adalah metode muroja'ah dan metode tabarak, metode muroja'ah berasal dari bahasa arab yaitu roja'a yarji'u yang artinya kembali, maksud kata kembali adalah kembali untuk mengingat hafalan yang telah dihafal (Herma et al., 2020; Rosida, 2020). TAUD Al- Fatihah menerapkan metode kombinasi antara metode muroja'ah dan metode tabarak.

Metode muroja'ah dilakukan oleh guru-guru ke pada anak setiap pagi hari dan saat akan pulang sekolah. Guru akan memutarkan spiker Al-Quran yang telah diprogram khusus untuk tahfidz. Pada saat muroja'ah, semua hafalan anak akan diulang dari awal sampai batas akhir hafalan yang telah diberikan oleh guru.Sedangkan metode tabarak yang diambil dari nama salah seorang anak yang pernah dinobatkan sebagai Hafidz termuda sedunia ketika berusia 5 tahun, beliau adalah anak dari Dr. Kameel Al Laboody dan Dr. Rasha yang juga Hafidz Qur'an (Hidayah, 2018).

Metode tabarak mulai diterapkan di TAUD Al-Fatihah pada anak Usia 3 tahun, dimana Metode Tabarok sendiri membagi pembelajaran menghafal kedalam 7 bagian. Masing-masing bagian dalam periode 4 bulan, berikut pembagian dari metode tabarak di TAUD Al-Fatihah. Level 1: menghafal Juz 30 dan pengenalan huruf-huruf Hijaiyah dengan harakat, Level 2: menghafal Juz 29 dan pengenalan huruf, ijaiyah yang sudah dirangkai. Level 3: Menghafal Al-Baqarah dan Ali Imran pada level ini anak-anak sudah menghafal sambil menunjuk bacaan di mushaf. Level 4: menghafal An Nisa sampai Al Anfal. Level 5: menghafal At Taubah sampai Thoha. Level 6: menghafal Al Anbiya sampai Faathir. Level 7: menghafal Yasin sampai At Tahrim.

Level awal pada metode tabarak, anak-anak lebih banyak mendengar, baik itu dari guru/orang tuanya ataupun dari murottal. Satu ayat bisa diulang sampai 5x dan anak-anak diminta untuk mendengarkan dengan seksama dan melihat bagaimana guru/orangtua mengucapkan tiap kata. Baru setelah itu anak-anak diminta melafalkan. Ketika muroja'ah, anak-anak dibantu dengan mendengarkan murattal tempo cepat dan ketika sarapan pun tetap sambil diperdengarkan bacaan Quran.

Metode Tabarak telah dirancang dengan sedemikian rupa untuk memudahkan anak dalam menghafal Qur'an, anak akan di perlihatkan ayat-ayat Al-Qura'an secara visual dengan menggunakan Televisi, laptop, infocus, dan spiker sebagai media bantu (Hidayah, 2018). Sehingga anak dapat dengan mudah menghafal, mengenal huruf dan mengingat ayat- per ayatnya. Hal ini dapat terlihat pada gambar 1. 


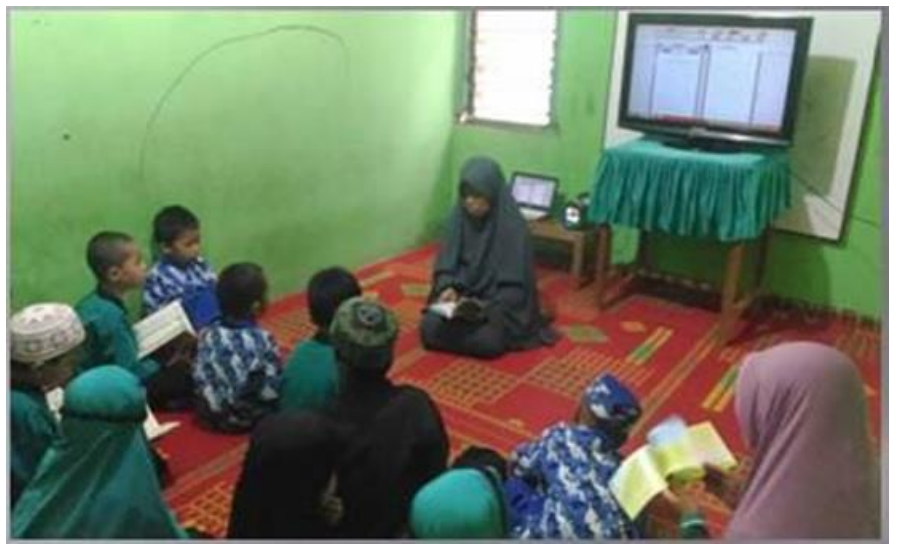

Gambar 1. Proses murojaah pagi dengan metode tabarak pada siswa Juz 27 dan 28

Berdasarkan gambar 1 dapat terlihat bahwa suasana murojaah para peserta didik TAUD yang berusia 6 tahun lebih teratur dan tenang. Dimana pada saat murojaah ini para peserta didik mendengarkan Murotal Al-Qur'an yang diperdengarkan melalui program ayat yang telah di program dengan metode tabarak. Pada gambar ini juga terlihat tenaga pengajar yang sedang memandu para peserta didik dalam menghafalkan AL-Qur'an.

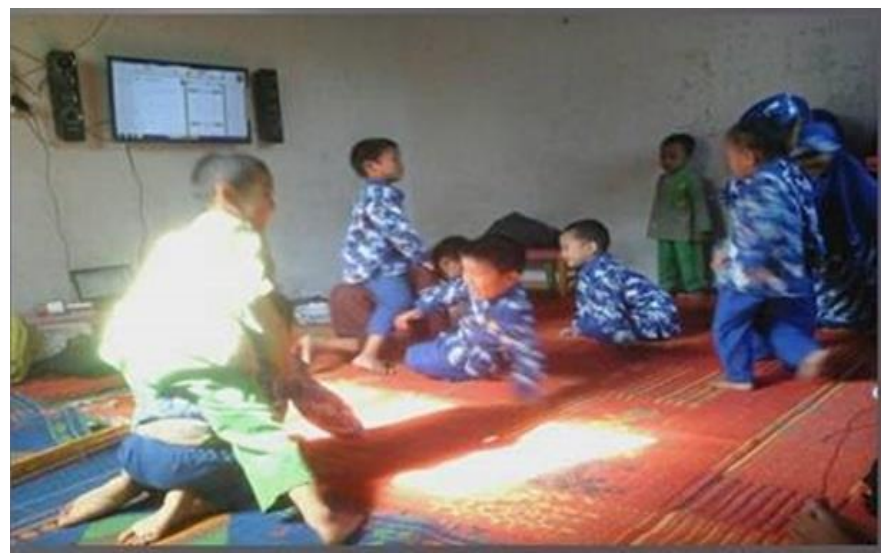

Gambar 2. Proses murojaah pagi dengan metode tabarak pada siswa Juz 29 dan 30

Berdasarkan gambar 2 dapat terlihat bahwa suasana murojaah para peserta didik TAUD yang berusia 3-5 tahun kurang teratur dan sulit untuk ditenangkan, tenaga pengajarpun dibuat kewalahan dengan tingkah lau peserta didik yang saat itu mulai sulit untuk fokus mendengarkan murotal dari program ayat yang ditampilkan pada layar LCD. Inilah yang juga menjadi kelemahan program tabarak, anak tidak dikelompokkan berdasarkan usia, akan tetapi dikelompokkan berdasarkan hafalan Al-Quran yang di milikinya. Jika dipandang dari segi kesiapan mental dan kematangan berfikir metode ini sangat tidak cocok digunakan di sekolah TAUD, karena para peserta didik yang usianya 4 tahun namun mempunyai kemampuan hafalan setara dengan anak usia 6 tahun akan berada 
di kelompok belajar yang sama, sehingga ini akan mempengaruhi perkembangan dan emosional para peserta didi yang lain.

Berdasarkan paparan tentang metode tabarak di atas terdapat beberapa kelemahan lainnya, dimana metode ini hanya dapat menggunakan media televisi yang telah terkoneksi dengan laptop untuk menampilkan program ayat yang telah di install pada laptop. Metode tabarak ini adalah tidak tersedianya program untuk pembelajaran tahsin bagi peserta didik, sehingga peranan guru dalam memandu pembelajaran tahsin masih sangat tinggi. Dalam kondisi pandemi COVID-19 ini, sangat tidak memungkinkan untuk para peserta didik belajar di sekolah. Oleh sebab itu melalui modul elektronik yang di rancang dalam kegiatan pengabdian masyarakat ini dapat membantu peserta didik belajar secara mandiri di rumah secara offline. Modul elektronik ini memadukan aplikasi camtasia untuk proses recording video para guru dalam pembelajaran tahsin.

Melalui video ini siswa dapat melihat gerakan mulut dan cara pengucapan dari masing-masing ayat yang di ajarkan dalam pembelajran tahsin. Sedangkan untuk tahfidz, para peserta didik juga dipandu dengan video dan audio dari para guru. Sedangkan untuk materi tahsin dan tahfidz dibuat dalam format pdf lalu di import ke aplikasi kavi soft untuk di edit dan di desain sehingga menjadi sebuah modul elektronik dengan format exe. Elekronik modul yang telah tersimpan dengan format exe dapat di buka di laptop dan smart phone secara offline, sehingga tidak membebankan orangtua murid. Melalui pelatihan yang diberikan dalam kegiatan pengabdian masyarakat ini, dapat meningkatkan kemampuan para tenaga pendidik dalam bidang IT, khususnya dalam pembuatan media pembelajaran elektronik yang menarik dan dinamis.

\section{METODE}

Untuk pelaksanaan pengabdian ini dilakukan dengan tahapan (i) Wawancara dan Diskusi dengan Mitra Terkait Masalah dan solusi yang ingin diberikan; (ii) Setelah Masalah dan solusi disepakati, maka ditunjuk anggota TIM PKM yang berkompeten dalam menangani masalah tersebut, jika bidang keahlian tim tidak sesuai maka Tim Mencarikan Pakar sebagai narasumber dari luar bidang keahlian. Selanjutnya untuk membantu data dan informasi yang dibutuhkan tim PKM, Tim Mitra juga Menunjuk Guru Penanggung jawab yang berkolaborasi dengan Tim PKM; (iii) Masing-masing Tim PKM yang telah dibagi tanggung jawabnya mulai berdiskusi dengan Tim Pendamping (Mhs, Pakar dan Tim Mitra); (iv) Masing-masing Tim mulai bekerja menyelesaikan Pekerjaan Masing-masing seperti, Membuat Media, Aplikasi, dan Modul Pelatihan, Sertifikat); (v) Seminar, 
WorkShop dan Implementasi Produk Aplikasi yang telah dibuat sesuai kebutuhan mitra. Untuk tahapan dan solusi yang dilakukan pada pengabdian ini dilihat pada gambar 3 .

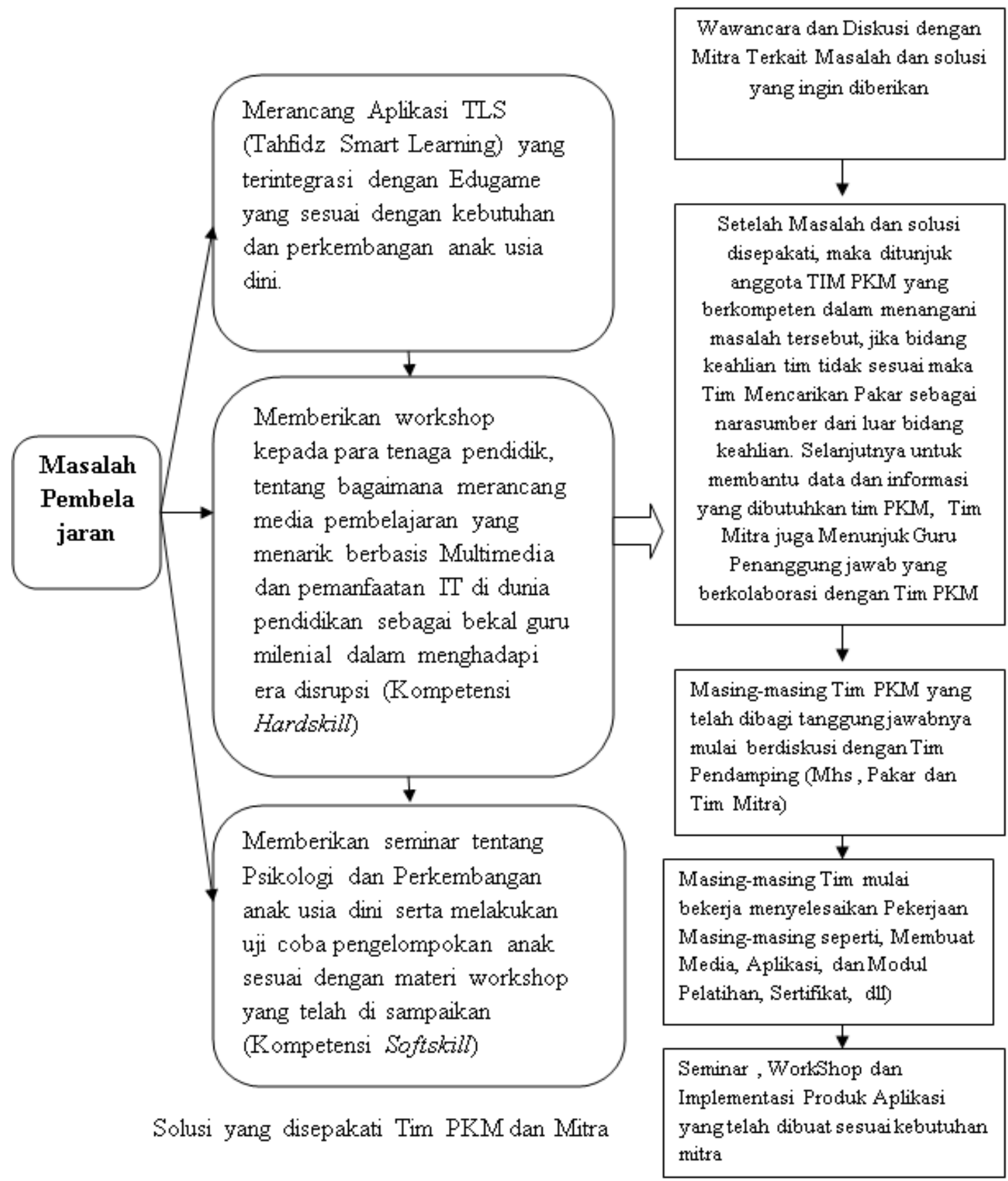

Gambar 3. Metode Pelaksanaan Kegiatan Pengabdian

\section{HASIL, PEMBAHASAN, DAN DAMPAK}

\section{Kegiatan Pra}

Tahap ini dilakukan pada hari Senin, 10 Agustus 2020. Kegiatan ini dilakukan di rumah kepala sekolah TAUD Al-Fatihah, dengan melakukan koordinasi dengan para guru terkait kegiatan pengabdian yang akan dilaksanakan pada bulan September. Kegiatan 
koordinasi ini berisi kesepakatan waktu pelaksanaan kegiatan, perangkat pembelajaran, materi ajar dan video pembelajran, serta perangkat pendukung lainnya seperti whiteboard, spidol, soundsystem, laptop dan microfone. Disamping koordinasi terkait perangkat pendukung dan perangkat pembelajaran yang perlu di persiapkan, ketua tim pengabdian juga melakukan koordinasi dengan kepala sekolah terkait jumlah tenaga pengajar yang akan di ikut sertakan dalam kegiatan ini, tujuannya adalah agar tim pengabdian dapat menghitung jumlah modul pelatihan dan alat tulis serta konsumsi yang nantinya perlu dipersiapkan. Hal ini dapat dilihat pada dokumentasi pribadi dari ketua tim pengusul.
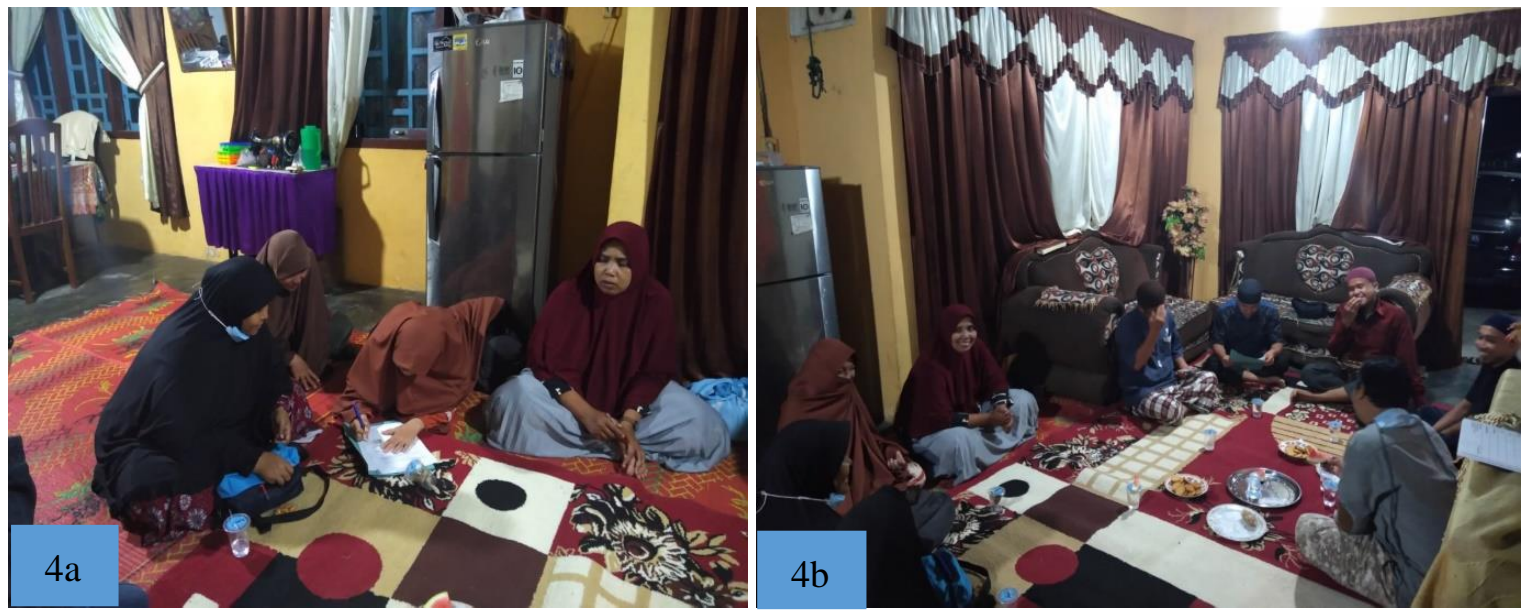

Gambar 4a. Proses Penanda tanganan Surat Kesedian Mitra, 4b. Proses Koordinasi Waktu Pelaksanaan dan Fasilitas yang dibutuhkan.

\section{Kegiatan Persiapan PKM}

Tahapan ini menjelaskan proses persiapan yang dilakukan oleh tim pengusul sebelum melakukan pelatihan, dimana ketua tim berperan didalam membagi tugas dari masing-masing anggota tim dan pendamping lapangan, disamping itu ketua tim pengusul menyampaikan hasil koordinasi yang telah dilakukan dengan mitra agar anggota dan pendamping lapangan mendapatkan gambaran tentang kondisi dan kebutuhan mitra serta mempersiapkan fasilitas pendukung sebelum pelatihan di laksanakan. Adapun kegiatan yang tim pengusul lakukan sebelum melakukan pelatihan adalah:

1. Mempersiapkan Modul, Pembuatan Aplikasi, Angket Pre Test dan Post Test.

Dokumentasi kegiatan mempersiapkan modul, pembuatan aplikasi, angket pre test dan post test gambar 5a. mempersiapkan modul, gambar 5b. persiapan pembuatan aplikasi, angket pre test dan post test. 

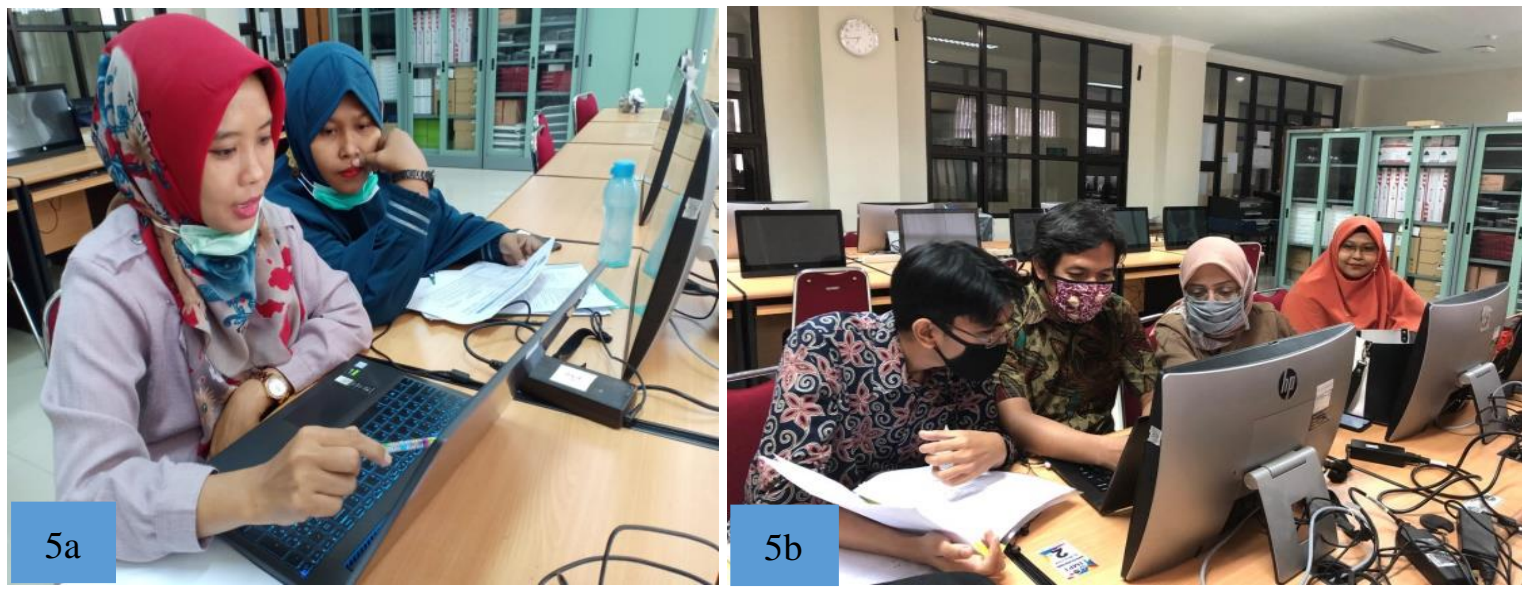

Gambar 5a. Mempersiapkan Modul, Gambar 5b. Persiapan Pembuatan Aplikasi, Angket Pre Test dan Post Test

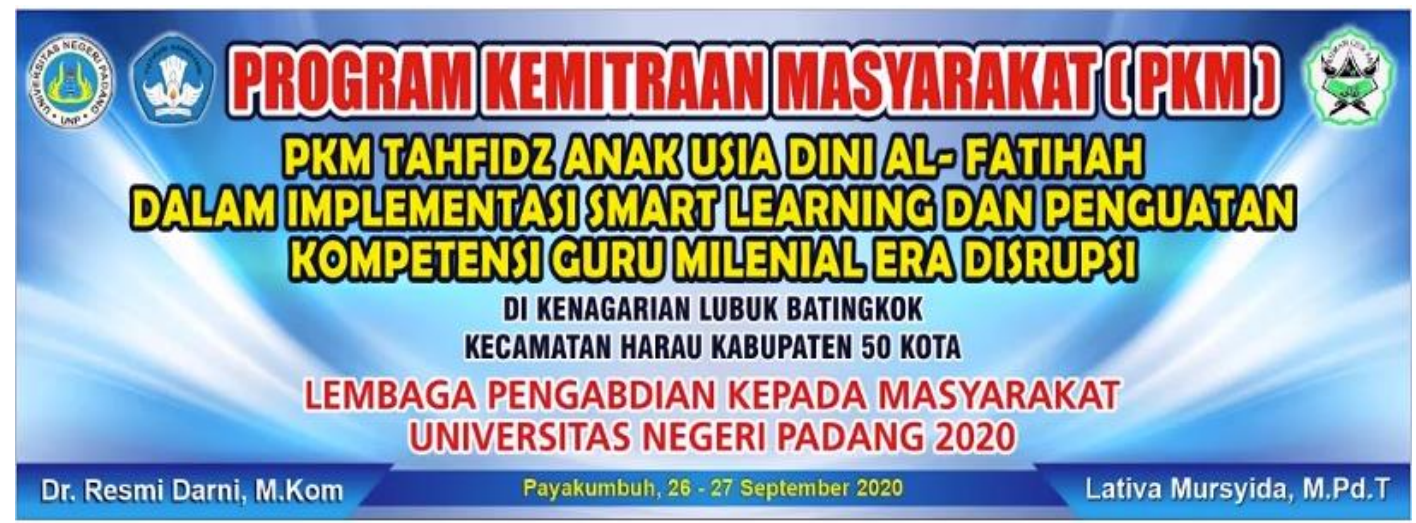

Gambar 6. Persiapan Spanduk Kegiatan

\section{Tahap Pelaksanaan Pelatihan}

Tahapan ini merupakan tahapan inti dari kegiatan PKM ini dimana tim pengusul dan pendamping lapangan melaksanakan kegiatan pelatihan kepada guru-guru tahfidz Rumah Qur'an Al-Fatihah di Kanagarian Lubuk Batingkok Kecamatan Harau Kabupaten 50 Kota. Kegiatan pelatihan ini dilaksanakan pada tanggal 26 - 27 September 2020, adapun hari pertama kegiatan dilaksanakan pada hari Sabtu, 26 September 2020 pukul 08.00 WIB dimulai dengan pembukaan oleh kepala sekolah, dilanjutkan dengan pemberian pre test, dan pemberian materi camtasia sebagai tahap awal pembuatan e-modul tahfidz yang nantinya akan upload pada smart learning, kegiatan pada hari pertama berakhir apa pukul 17.00 WIB. 


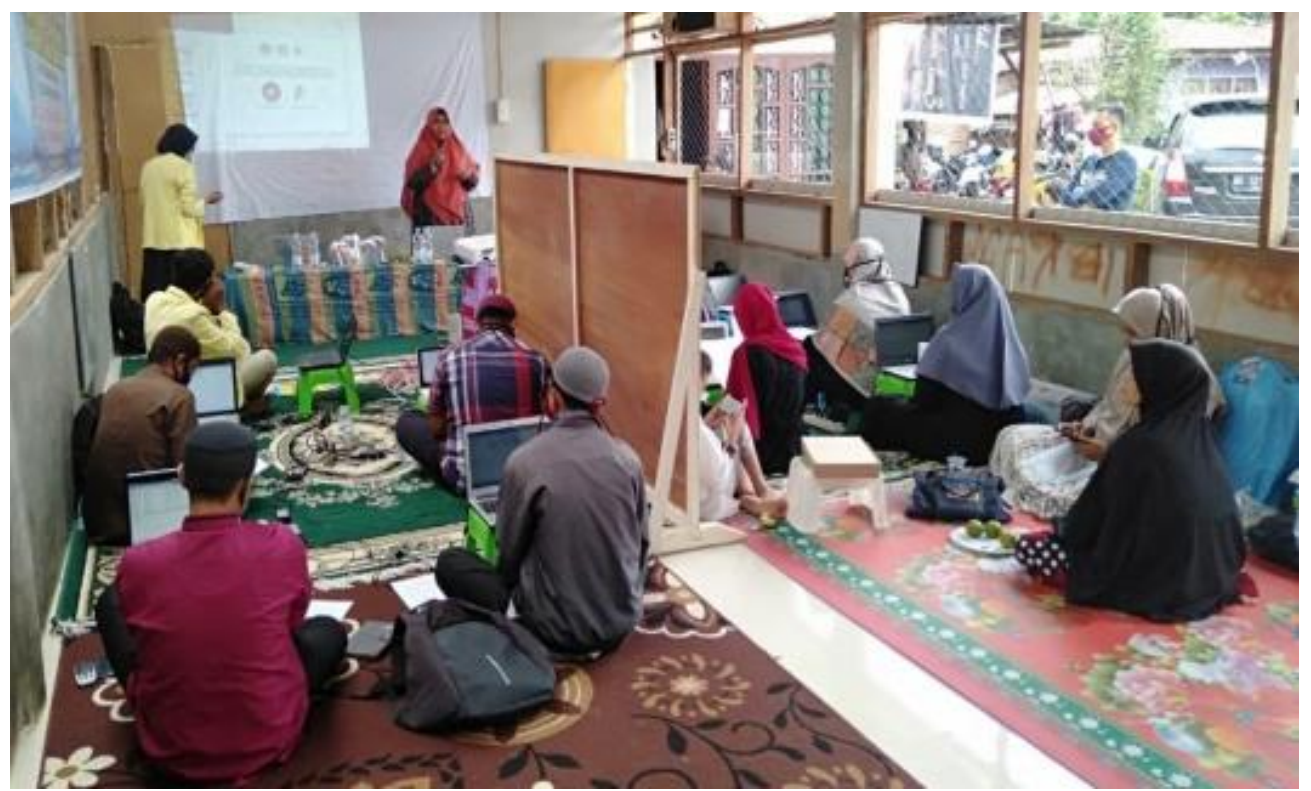

Gambar 7. Penjabaran Materi Pembuatan e-book Tahsin dan Tahfidz bagi para guru

Tahapan selanjutnya dilaksanakan pada hari ke dua yaitu pada hari Minggu, 27 September 2020, adapun kegiatan yang dilaksanakan pada hari tersebut adalah pemberian materi Kvi Soft Fliep Book Maker untuk proses pembuatan e-book Tahsin dan Tahfidz bagi para guru, pada tahapan ini guru-guru diminta untuk membuat video pembelajaran tahsin dan tahfidz yang menarik khusu bagi siswa/i PAUD Rumah Qur'an Al-Fatihah, adapun output atau tampilan produk yang dihasilkan dari kegiatan ini adalah

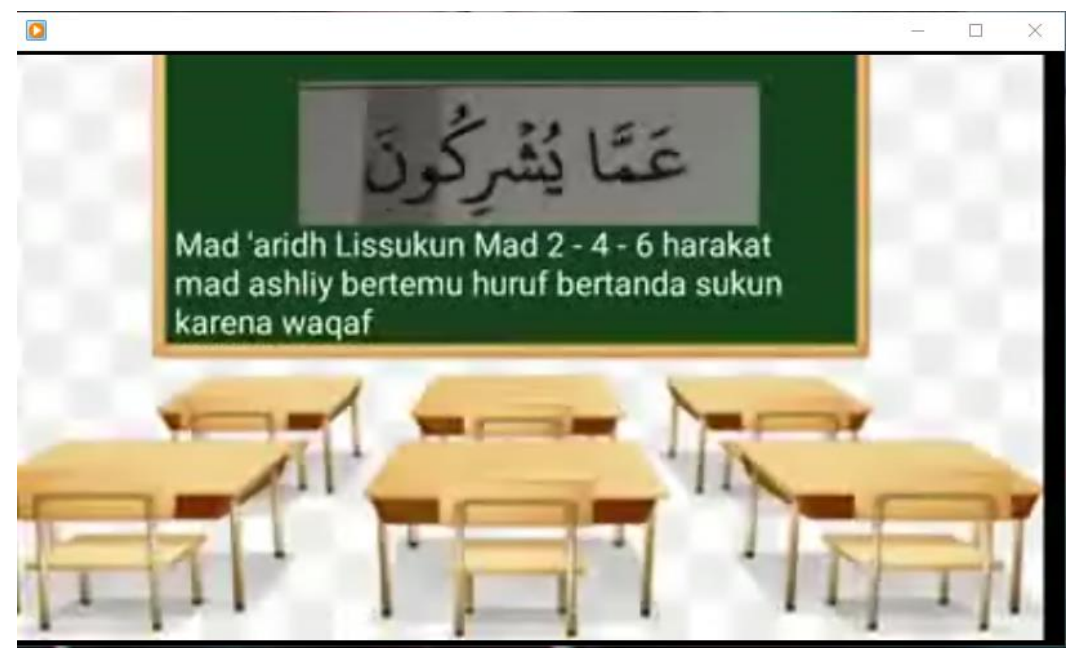

Gambar 8. Output Pembelajaran Tahfidz

Berdasarkan pelatihan yang telah diberikan kepada para tenaga pengajar di TAUD AlFatihah terdapat peningkatan hasil pembelajaran $21 \%$; 


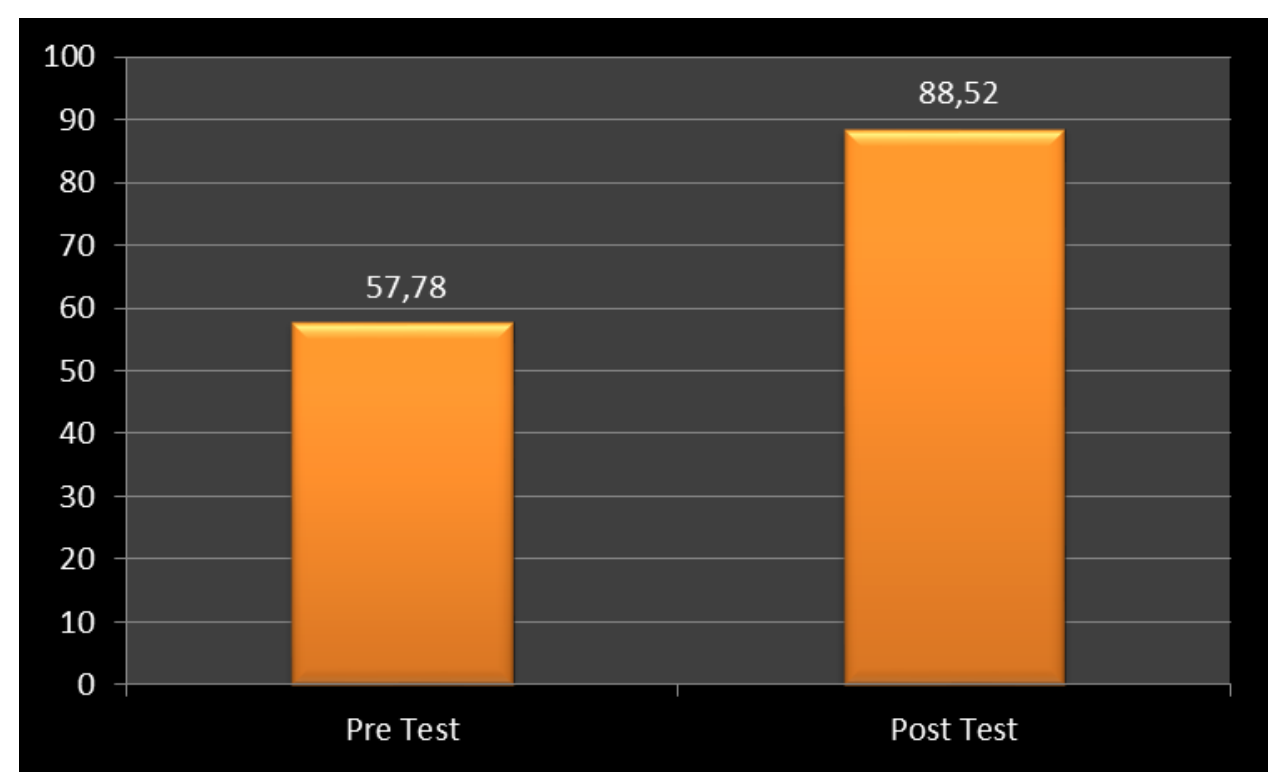

Gambar 9. Hasil Pre Test dan Post Test Tenaga Pengajar

Dimana pada tahap awal pelatihan diperoleh nilai rata-rata pre test sebesar 57,78 sedangkan setelah dilakukan pelatihan dan pendampingan diperoleh nilai post tes sebesar 88,52 . Hal ini membuktikan bahwa pelatihan dan pendampingan yang diberikan kepada guru-guru di TAUD AL-Fatihah dapat meningkatkan kompetensi IT dan pemahaman media ajar berbasis multimedia.

\section{SIMPULAN}

Pembuatan e-modul tahsin tahfizh ini tidak terlepas dari fasilitas multimedia, untuk menampilkan suara dan video dari guru yang akam memberikan materi tahsin dan tahfidz. Hal ini bertujuan untuk mempermudah siswa dalam memahami setiap ucapan dan setiap pelafasan dari ayat yang dipelajari. Dibutuhkan kesabaran ketika pembuatan video, serta kemampuan seni editing dari guru untuk mempercantik tampilan media pembelajaran.Berdasarkan hasil pelatihan yang telah dilakukan terdapat peningkatan kemampuan dan pemahaman terhadap IT dari tenaga pengajar sebesar $21 \%$ yang dibuktikan dari peningkatan hasil rata- rata pre test dan post test yang telah dilakukan. Dimana hasil pre test menunjukkan angka rata-rata pemahaman terhadap IT sebesar 57,78 sedangkan setelah dilakukan pelatihan terlihat peningkatan rata-rata nilai post test sebesar 88,52 . 


\section{DAFTAR PUSTAKA}

Herma, T., Kusyairy, U., \& Rusdi, M. (2020). Analisis Penerapan Metode Tabarak Menghafal Al-Qur'an Juz 30 Di Sekolah Tahfidz Al-Husna Balita Dan Anak Makassar. Indonesian Journal Of Early Childhood Education, 3(1), 37-48.

Hidayah, A. (2018). Metode Tahfidz Al-Qur'an Untuk Anak Usia Dini (Kajian Atas Buku Rahasia Sukses 3 Hafizh Quran Cilik Mengguncang Dunia). Jurnal Studi Ilmu-Ilmu Al-Qur'an Dan Hadis, 18(1), 51. Https://Doi.Org/10.14421/Qh.2017.1801-04

Nugraha, A., Ritayanti, U., Siantayani, Y., \& Maryati, S. (2015). Pedoman Pengelolaan Pembelajaran Anak Usia Dini. Jakarta: Direktorat Pembinaan Pendidikan Anak Usia Dini

Ridho, R., Markhamah, \& Darsinah. (2015). Pengelolaan Pembelajaran Pendidikan Anak Usia Dini (PAUD) Di Kb “Cerdas” Kecamatan Sukorejo Kabupaten Kendal. Jurnal Penelitian Humaniora, 16(3), 59-69.

Rosida, Hailafur (2020) Penerapan Metode Tabarak Dalam Meningkatkan Hafalan Para Remaja Di Rumah Tahfidz Gemilang Indonesia Cabang Salatiga Tahun 2019. Other thesis, IAIN SALATIGA. http://e-repository.perpus.iainsalatiga.ac.id/id/eprint/8069

Sugeng, H. M., Tarigan, R., \& Sari, N. M. (2019). Gambaran Tumbuh Kembang Anak Pada Periode Emas Usia 0-24 Bulan Di Posyandu Wilayah Kecamatan Jatinangor. Jsk, 4(3), 96-101. 